\title{
Ongoing COVID-19 pandemic: Current Status of Nepal
}

\author{
*Ved Prakash Mishra', Sunil Paudel², Suraj Twanabasu³, Kajol Thapa ${ }^{4}$, Susan Kusma ${ }^{5}$
}

\begin{abstract}
Author Info:
1 Lecturer, Department of Public Health, Nobel College, Pokhara University, Sinamangal, Kathmandu, Nepal

${ }^{2}$ Lecturer, Department of

Microbiology, Nobel College, Pokhara University, Sinamangal, Kathmandu, Nepal

${ }^{3}$ Medical Laboratory Technologist, Department of Pathology, Vayodha Hospital, Balkhu, Kathmandu, Nepal ${ }^{4}$ Coordinator, Department of Medical Laboratory Technology, Kathmandu School of Medical Technology, Ratopul, Kathmandu, Nepal ${ }^{5}$ Medical Laboratory Technologist, Department of Pathology, Lalupate Medical Center Pvt Ltd, Gaushala, Kathmandu, Nepal
\end{abstract}

\section{*Corresponding Author:} Mr. Ved Prakash Mishra Department of Public Health, Nobel College, Pokhara University, Sinamangal, Kathmandu, Nepal Phone No.: +977-9860005313 Email: mishraved66@gmail.com

\section{Dear Editor,}

Emerging and remerging pathogens are worldwide difficulties for public health. ${ }^{1}$ Coronaviruses are enveloped positive-sense single-stranded RNA viruses that are dispersed extensively among people, different warmblooded creatures, and flying creatures that cause respiratory, enteric, hepatic, and neurologic diseases. ${ }^{2,3}$ Six coronavirus species are known to cause human illness like 229E, OC43, NL63, and HKU1, SARS-CoV, and MERS - CoV. ${ }^{4}$ SARS-CoV-2 is the seventh member of the coronaviruses that infect humans.5 Most of the symptoms of COVID-19 are similar to other respiratory illnesses like influenza SARS-CoV, MERS-CoV. ${ }^{6}$ Common symptoms of SARS-CoV-2 include fever, chills, muscle aches, diarrhea, and dry cough. On the other hand, severe forms of symptoms include pneumonia, heart failure, and liver failure. ${ }^{7,8}$ Given the high prevalence and wide distribution of coronaviruses, the huge hereditary decent variety and successive recombination of their genomes, and expanding humancreature interface exercises, novel coronaviruses are probably going to develop intermittently in people attributable to visits to cross-species contaminations and incidental overflow events..$^{910}$ On January 30, the World Health Organization (WHO) declared the ebb and flow flare-up that began in Wuhan, China as a Public Health Emergency of International Concern, while prescribing against movement or exchange interruptions to and from China. ${ }^{11}$ The progressing pandemic of coronavirus ailment 2019 (COVID-19) is brought about by severe acute respiratory disorder coronavirus 2 (SARS-CoV-2). ${ }^{12}$ As of 02 May 2020, 3,267,184 instances of COVID-19 have been accounted for in more than 200 nations and regions, bringing about 229,971 deaths. ${ }^{13}$

Keywords: COVID-19 Pandemic, Coronavirus, Status, Nepal

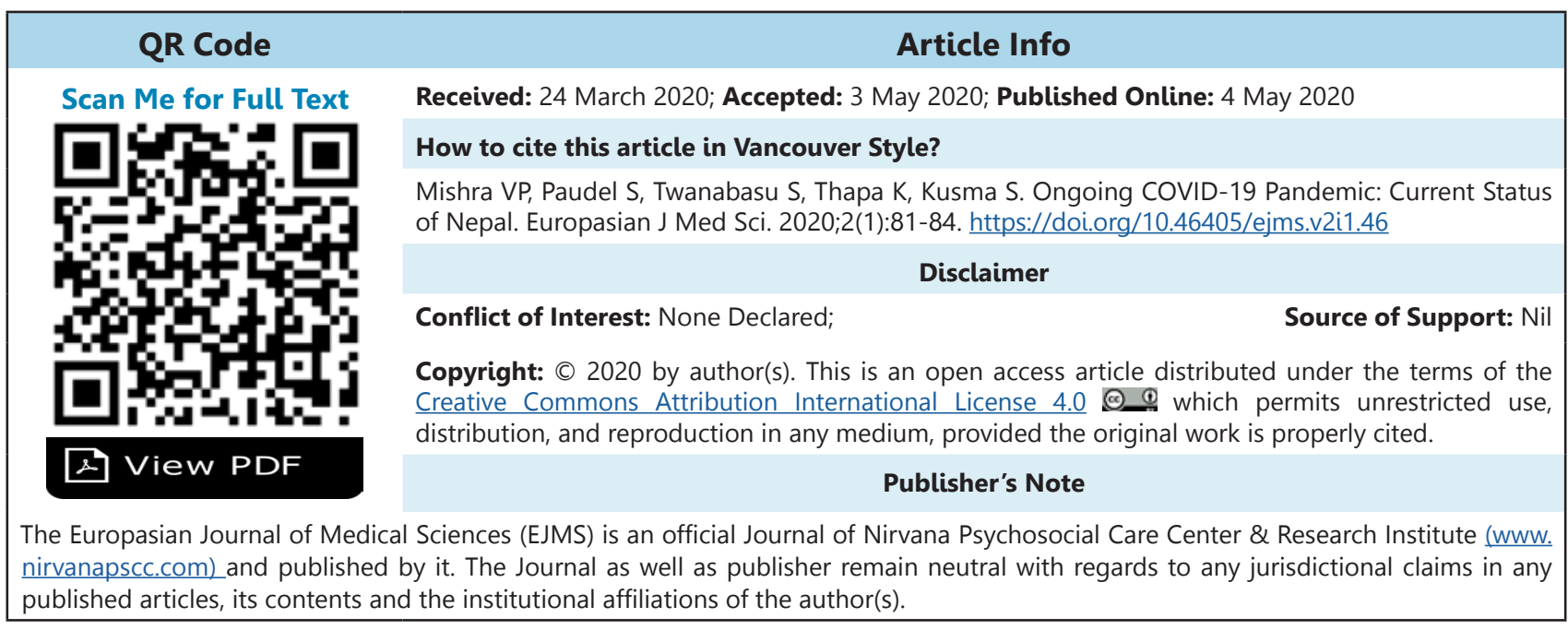


The COVID-19 pandemic was certified to have spread to Nepal when its first positive case was reported on January 13, 2020, in a 32 years old Nepalese student based at Wuhan University of Technology, with no known comorbidities who had returned to Nepal. ${ }^{14}$ The patient introduced at a hospital in Kathmandu, complaining of cough. He had developed symptoms 6 days before his travel to Nepal. Throat swabs taken from the patient were found to be positive for COVID-19 using realtime quantification assays performed at the WHO laboratory in Hong Kong. Fortunately, the patient recovered 13 days post-exposure. ${ }^{15}$ The subsequent case was affirmed on 23 March 2020. Seven extra cases have been affirmed, one each in Kathmandu and Kanchanpur locale, two in Baglung, and three in Kailai.

Seven of the eight dynamic cases included individuals who had as of late returned from abroad; the principal instance of neighborhood transmission was affirmed on 4 April in a 34-yearelderly person from Kailali, who is known to be a relative of one of the previous tainted people. Because of this first neighborhood transmission, Nepal additionally entered the second phase of the COVID-19 pandemics.On 17 April, 14 new cases were affirmed, 12 of them, Indian nationals from Delhi, isolated in Udayapur. One progressively Indian national tried constructive on 18 April and 11 additional individuals affirmed positive for COVID-19 on 21 April in Udayapur. Two additional cases affirmed positive in Udayapur on 23 April. In the Udayapur cases, Nepal demonstrated a huge risk from the India open border. As of 2 May 2020, 59 cases have been reported, of which 16 cases recovered. A nationwide lockdown became effective on 24 March and was planned to end on 7 May. ${ }^{17}$

Nepal is a small landlocked country between China on the northern side and India in the east, west, and south. ${ }^{18}$ The world is on a high alarm: fringes are shutting and stringent measures are being taken to confine the spread of COVID-19. ${ }^{19}$ Nepal set up health-desks at the international airport just as on the outskirts checkpoints with India, beginning in mid-January. Land fringes with India just as China were later totally closed, and every single global flight suspended. Every single scholastic assessment was dropped, and schools and

Universities were shut. Isolate focuses and brief emergency clinics are being arrangement the nation over. Research center offices are being redesigned and extended. Emergency clinics have been setting up ICU units and seclusion beds. Nepal dropped its worldwide limited time exercises identified with Visit Nepal Year 2020. Its economy is required to be seriously influenced by the pandemic due to its effect on remote business, the travel industry, assembling, development, and trade. ${ }^{20}$

As indicated by The Kathmandu Post, before the pandemic, medical clinics in Nepal had scarcely any ICU beds (only three in Teku Hospital), which were quite often occupied, with individuals in vital circumstances usually having to wait for the beds to come to be empty. It detailed specialists as saying that it is beside difficult to concede new patients to ICU when they need them. ${ }^{21}$ There are various public health challenges in controlling the spread of COVID-19 in the South Asian region, including Nepal. Moreover, there is limited coordination among different stakeholders in healthcare management with few policies in place for infection prevention and control (IPC), shortage of testing kits, medical supplies, personal protective equipment, and poor reporting are major challenges to be tackled in the case of the COVID-19. Nepal is extremely difficult to maintain social distancing, poor hygiene, and lower (health) literacy rates. Additionally, some COVID-19 cases remain asymptomatic, so it is difficult to predict the severity of the outbreak. ${ }^{15,16}$

As updates on novel coronavirus infectious diseases in China have broken, concerns were brought up in Nepal over the high potential hazard, the need to actualize preventive measures, and extreme absence of essential clinical gear and foundation. As indicated by Baburam Marasini, the chief of the Epidemiology and Disease Control Division, Nepal does not have any twofold taxi ambulances to ship exceptionally irresistible patients securely, disengagement wards in medical clinics, or biosafety level-3 or better research centers expected to test for profoundly infectious diseases. ${ }^{22}$

Sukraraj Tropical and Infectious Disease Hospital is a relegated fundamental crisis facility for the treatment of COVID-19.A transitory emergency clinic, named Bharatpur Corona Special Hospital has been built up in the Chitwan District. The Nepal Public Health Laboratory in Kathmandu was the main lab equipped for testing for the infection starting on 15 March 2020; it was fit for leading 500 tests per week and had a load of 1,000 viral 
vehicle media (VTM) packs for shipping tests to be tested. ${ }^{23,24}$ It had led to more than 10,000 real-time PCR tests.

Nepal's pharmaceutical industry has been affected because of the absence of crude materials, as various basic fixings were recently imported from Hubei. ${ }^{25,26}$ Nepal confronted the possibility of a potential deficiency of fundamental meds when India forced limitations on the fare of 26 sorts of crude materials, including basic medication referring to a disturbance in the production network from Hubei; anyway, India later consented to loosen up limitations if there should be an occurrence of Nepal and requested that the Nepalese government gave a rundown of names and amounts of basic drugs that are expected to supply to Nepal. ${ }^{27}$

Dixit, who has postgraduate degrees in immunology and biotechnology, accepts that individuals are not getting truly sick since Nepal is encountering a less serious strain of the infection, as well as Nepalese, do have more grounded resistant systems. ${ }^{28}$ Buddha Basnyat, a doctor at Patan Hospital, out and out rejects the thought of Nepali invulnerability. He says: "I think it is impulsive to accept that we are somehow immune - there is no legitimate purpose behind this. I think it is a silly, wild guess." ${ }^{28}$ In the wake of being in lockdown now for almost six weeks, COVID-19 cases are increasing due to people hiding their infections and also due to asymptomatic conditions. Nepal will be increased monitoring of hidden cases and also increase realtime PCR tests to confirm actual cases.

\section{In conclusion,}

Nepal is as of now in the second phase of COVID-19 transmission and the following stage will be serious. The government is focusing its tests on Western Nepal and the terai locale, where there have been returning Nepalese workers from India. Even though the outskirt should be shut, it is as yet workable for individuals to sneak past. Nepal can't be self-sufficient, and our solitary possibility of containing it is to prevent concealed cases from contaminating others with a significantly stricter lockdown.

\section{REFERENCES}

1. Gao GF. From "A"IV to "Z"IKV: attacks from emerging and re-emerging pathogens. Cell 2018;172:11571159. https://doi.org/10.1016/j.cell.2018.02.025
2. Weiss SR, Leibowitz JL. Coronavirus pathogenesis. Adv Virus Res 2011;81:85-164. https://doi. org/10.1016/B978-0-12-385885-6.00009-2

3. Masters PS, Perlman S. Coronaviridae. In: Knipe DM, Howley PM, eds. Fields virology. 6th ed. Lippincott Williams \& Wilkins, 2013:825-58.

4. Su S, Wong G, Shi W, et al. Epidemiology, genetic recombination, and pathogenesis of coronaviruses. Trends Microbiol2016:24:490-502. https://doi. org/10.1016/j.tim.2016.03.003

5. Zhu N, Zhang D, Wang W, Li X, Yang B, Song J, et al. A novel coronavirus frompatients with pneumonia in China, 2019. N Engl J Med. 2020;382:727-33. https:// doi.org/10.1056/NEJMoa2001017

6. Mayo Clinic Staff. Coronavirus disease 2019 (COVID-19). Mayo Clinic. Accessed 15 April 2020. Link

7. Jennifer Robinson. What Is SARS?. WebMD. Accessed 7 February 2018. Link

8. Mayo Clinic Staff. Severe acute respiratory syndrome (SARS). Mayo Clinic. Link

9. Cui J, Li F, Shi ZL. Origin and evolution of pathogenic coronaviruses. Nat Rev Microbiol2019;17:181-192. https://doi.org/10.1038/s41579-018-0118-9

10. Wong G, Liu W, Liu Y, Zhou B, Bi Y, Gao GF. MERS, SARS, and Ebola: the role of super-spreaders in infectious disease. Cell Host Microbe 2015;18:398401. https://doi.org/10.1016/j.chom.2015.09.013

11. WHO. Statement on the second meeting of the International Health Regulations (2005) Emergency Committee regarding the outbreak of novel coronavirus (2019-nCoV), [Internet]. 2020 [cited 2020 Feb 08]. Link

12. Coronavirus disease in 2019. World Health Organization. Retrived 15 March 2020.

13. Coronavirus disease 2019 (COVID-19) situation report-103. World Health Organization. Retrived 02 May 2020.

14. Bastola A, Sah R, Rodriguez-Morales AJ, Lal BK, Jha $\mathrm{R}$, Ojha $\mathrm{HC}$, et al. The first 2019 novel coronavirus case in Nepal. Lancet Infect Dis. 2020;20:279-280. https://doi.org/10.1016/S1473-3099(20)30067-0

15. Asim M, Sathian B, van Teijlingen E, Mekkodathil A, Subramanya SH, Simkhada P. COVID-19 Pandemic: Public Health Implications in Nepal. Nepal J Epidemiol. 2020;10(1);817-820. https://doi. org/10.3126/nje.v10i1.28269

16. Ranish Shrestha, Sunil Shrestha, Pratik Khanal, K C Bhuvan, Nepal's First Case of COVID-19 and public health response, Journal of Travel Medicine.024. Full Text

17. MOHP Nepal. Corona Info. MOHP Nepal. Retrieved 02 May 2020. Link 
18. Devkota, Himnath. Nepal-China Rasuwagadhi border point to be sealed for 15 days from Wednesday. My Republica. Retrieved 16 March 2020.

19. The Covid-19 outbreak so far and how Nepal can prepare for the worst. The Kathmandu Post. Updated at: March 30.

20. Govt to carry out impact assessment of coronavirus on the economy. The Himalayan Times. 6 March 2020. Retrieved 24 March 2020.

21. Nepal's hospitals have no ICUs to treat coronavirus patients, doctors say. The Kathmandu post.com. Retrieved 12 March 2020.

22. Nepal vulnerable to new China virus, warn doctors. The Himalayan Times. 16 January 2020. Retrieved 16 March 2020.

23. Stock of kits to transport coronavirus samples limited. The Himalayan Times. 16 March 2020. Retrieved 24 March 2020.
24. Central laboratory is equipped to test 500 Covid-19 cases a week, but that is far too low, say public health experts. The Kathmandupost.com. Retrieved 24 March 2020.

25. Nepali economy starts to feel the pinch as coronavirus spreads. The Kathmandu post.com. Retrieved 11 March 2020.

26. India seeks list of essential drugs that Nepal needs. The Himalayan Times. 6 March 2020. Archived from the original on 7 March 2020. Retrieved 11 March 2020.

27. AsmitaPriyadarshiniKhatiwada and Sunil Shrestha, Pharmacy Patronage: Identifying the Roles of Nepalese Pharmacists in Tacking COVID-19, J. Pure Appl. Microbiol., May 2020; 14(SplEdn.). https://doi. org/10.22207/JPAM.14.SPL1.31

28. Marty Logan. Covid-19, Nepal and the hygiene hypothesis. Nepal Times. Accessed 22 March 2020. Available at:https://www.nepalitimes.com/opinion/ covid-19-nepal-and-the-hygiene-hypothesis/ 